\title{
Parâmetro microbiológico de queijos produzidos e comercializados no Brasil: revisão
}

\section{sistemática}

\author{
Microbiological parameter of cheeses produced and marketed in Brazil: Systematic review \\ Parámetro microbiológico de quesos producidos y comercializados en Brasil: Revisión sistemática
}

Recebido: 2310/2021 | Revisado: 31/10/2021 | Aceito: 06/11/2021 | Publicado: 10/11/2021

\author{
Magnólia Carneiro de Oliveira \\ ORCID: https://orcid.org/0000-0002-3741-0076 \\ Instituto Federal de Educação, Ciência e Tecnologia do Ceará, Brasil \\ E-mail: magnoliacarneirooliveira@gmail.com \\ Maria Juciene Lima Chaves \\ ORCID: https://orcid.org/0000-0002-8825-0594 \\ Instituto Federal de Educação, Ciência e Tecnologia do Ceará, Brasil \\ E-mail: jucienelima.juju@gmail.com \\ Felipe Kairo de Sousa Lima \\ ORCID: https://orcid.org/0000-0001-6728-3007 \\ E-mail: felipekairo@yahoo.com.br \\ Antônia Lucivânia de Sousa Monte \\ ORCID: https://orcid.org/0000-0003-2504-5136 \\ Instituto Federal de Educação, Ciência e Tecnologia do Ceará, Brasil \\ E-mail: lucivania@ifce.edu.br \\ Luana Guabiraba Mendes \\ ORCID: https://orcid.org/0000-0001-8184-8588 \\ Instituto Federal de Educação, Ciência e Tecnologia do Ceará, Brasil \\ E-mail: luanagmendes@gmail.com
}

\begin{abstract}
Resumo
Leite e derivados são alimentos muito suscetíveis a ataques de microrganismos. Sua fiscalização no Brasil está a cargo das Inspeções Municipais, Estaduais ou Federais, sendo a verificação da qualidade higiênico-sanitária dos alimentos uma atividade de extrema importância. A contaminação microbiológica em processamento de alimentos aumenta consideravelmente o risco de doenças de origem alimentar por contaminação cruzada. Portanto, a segurança na produção, embalagem e armazenamento de queijos, pode ser avaliada através da avaliação da qualidade microbiológica. O presente artigo tem como objetivo propor uma revisão sistemática dos parâmetros microbiológicos de queijos produzidos e comercializados no Brasil, observando a qualidade microbiológica, tendo como base de dados os artigos publicados entre os meses de janeiro de 2014 e agosto de 2021 nas plataformas de busca do Google Acadêmico, Scielo e Periódicos CAPES. Diante de análises avaliadas, constatou-se que em parâmetros primários evidencia-se a direta correlação entre as boas práticas de higiene, juntamente com o manuseio correto da matériaprima e aplicação das normas sanitárias, com uma menor carga microbiológica presente nas amostras. Com base nos trabalhos analisados, confere-se a eficiência que a implementação das práticas corretas de higiene promove na diminuição dos riscos de surtos alimentares. Ressalta-se que, mesmo a existência da flora bacteriana a presença de agentes externos patógenos se constitui como um grande problema.
\end{abstract}

Palavras-chave: Microbiológica; Alimentos; Leite e derivados.

\begin{abstract}
Milk and dairy products are foods more susceptible to suffer attacks from microorganisms. The inspection of these foods in Brazil is made by the Municipal, State or Federal inspectors and this verification of the hygienic-sanitary quality is an extremely important activity. Microbiological contamination during the food process increases the risk of foodborne cross-contamination diseases. Therefore, the safety in the production, packaging and storage of cheeses can be verified by evaluating the microbiological quality. This article proposes a systematic review of the microbiological parameters of cheeses produced and sold in Brazil and the analysis of their microbiological quality. In order to accomplish this review, we based on different articles published from January 2014 to august 2021 and found on Academic Google platform, Scielo and CAPES periodicals. According to the analysis, we found that, in primary parameters, there is a direct correlation between good hygiene practices in the correct handling of raw materials and application of sanitary norms resulting in a lower microbiological load present in the samples. In this way, the efficiency of the implementation of correct hygiene practices promotes a reduction in the risk of foodborne outbreaks. Finally, we note which in spite of the existence of bacterial flora, the presence of external pathogens is a major problem.
\end{abstract}


Keywords: Microbiological; Foods; Milk and dairy products.

\section{Resumen}

La leche y los productos lácteos son muy susceptibles al ataque de microorganismos. Su inspección en Brasil está a cargo de Inspecciones Municipales, Estatales o Federales, y la verificación de la calidad higiénico-sanitaria de los alimentos es una actividad de suma importancia. La contaminación microbiológica en el procesamiento de alimentos aumenta considerablemente el riesgo de enfermedades por contaminación cruzada transmitidas por los alimentos. Por lo tanto, la seguridad en la producción, envasado y almacenamiento de quesos se puede evaluar evaluando la calidad microbiológica. Este artículo tuvo como objetivo proponer una revisión sistemática de los parámetros microbiológicos de los quesos producidos y comercializados en Brasil, observando la calidad microbiológica, a partir de artículos publicados entre Janeidor 2016 y agosto de 2021 en las plataformas de búsqueda Google Scholar, Scielo y Publicaciones periódicas CAPES. Dados los resultados obtenidos, se encontró que en los parámetros primarios existe una correlación directa entre las buenas prácticas de higiene, junto con el correcto manejo de las materias primas y la aplicación de las normas sanitarias, con una menor carga microbiológica presente en las muestras. Con base en los trabajos analizados, es posible verificar la eficiencia que promueve la implementación de prácticas correctas de higiene en la reducción del riesgo de brotes alimentarios, así como, es posible observar los índices aceptables de presencia de microorganismos durante el proceso de maduración. del queso coalho. Es de destacar que, incluso la presencia natural de colonias bacterianas que constituyen e incluso colaboran en la formación del producto, la presencia de patógenos externos es un problema importante.

Palabras clave: Microbiológico; Alimentos; Leche y derivados.

\section{Introdução}

A higiene alimentar corresponde ao conjunto de medidas adequadas para assegurar as características dos alimentos, como inocuidade, salubridade e conservação desde o plantio, produção ou fabricação, até o consumo (Martins et al., 2014). De acordo com a Comissão do Código Sanitário da Junta da Organização das Nações Unidas para Alimentação e Agricultura (FAO, do inglês Food and Agriculture Organization of the United Nations) e da Organização Mundial da Saúde (OMS), a higiene dos alimentos compreende as medidas preventivas necessárias na preparação, manipulação, armazenamento, transporte e venda, para garantir produtos seguros e adequados ao consumo humano.

No contexto da higiene alimentar estão as Boas Práticas de Fabricação (BPF) que estão relacionadas a procedimentos necessários para garantir os padrões mínimos de qualidade de produtos e serviços na área da alimentação. Para minimizar o risco de contaminação, todo estabelecimento produtor, industrializador e/ou comercializador de alimentos deve atender a essas recomendações (Nonato et al.,2012).

Como forma de monitorar a higiene alimentar, algumas análises microbiológicas podem fornecer informações importantes sobre as condições higiênicas, como exemplo disso, tem-se as bactérias do grupo coliforme, que são utilizadas como indicadoras de condições higiênico-sanitárias na água e nos alimentos. A presença de microrganismos indicadores como Escherichia coli em produtos processados indica, provavelmente, contaminação posterior ao processamento e pode sugerir uso de práticas inadequadas de manipulação e higiene (Souza et al., 2017).

Outro microrganismo importante nesse quesito é bactéria Staphylococcus aureus, que é um patógeno humano capaz de acarretar diferentes doenças com consequências para a saúde humana através da veiculação de suas toxinas através do leite. O consumo de alimentos com a pré-produção da enterotoxina pela bactéria é uma das intoxicações alimentares que mais acometem pessoas no mundo (Oliveira \& Rezende, 2012).

O queijo é um dos derivados lácteos mais consumidos no mundo. De acordo com a FIL/IDF (2020), os laticínios mais consumidos no mundo são os lácteos frescos, que incluem leite fluido e iogurte, os quais respondem por 17\% do consumo mundial de lácteos. Em seguida, tem-se manteiga, com 15\% do consumo, e queijos com 14\%. No Brasil, os queijos também são muito apreciados. Conforme a Pesquisa de Orçamentos Familiares (POF) do IBGE, eles perdem apenas para o leite fluido, representando quase $10 \%$ dos lácteos consumidos no País.

A produção e o consumo de queijos têm aumentado nos últimos anos no país. Diversos fatores favorecem o consumo 
desse alimento, por ser considerado saudável pela sua composição nutricional contendo proteínas de boa qualidade, pouca gordura e por ser adequado para todas as idades. No entanto, esses produtos podem se tornar fonte de veiculação de microrganismos patogênicos quando produzidos, manipulados ou armazenados sem os devidos cuidados higiênico-sanitários.

A ingestão de alimentos contaminados com patógenos provenientes de manipulação e processamento inadequados torna-se um dos riscos que mais necessitam de atenção para a saúde coletiva. Desse modo, para que os queijos produzidos no Brasil apresentem boa qualidade microbiológica e sejam considerados aptos para o consumidor é necessário garantir a adoção de padrões higiênico-sanitários durante o processamento ou produção da matéria prima, manipulação e comercialização desses produtos.

Nesse contexto, algumas análises microbiológicas podem ser empregadas para investigar a contaminação por microrganismos indicadores. Assim, considerando-se a cultura do consumo de queijos no Brasil, o estudo sobre a qualidade desse produto disponível ao consumidor faz-se necessário, bem como uma revisão sistemática dos parâmetros microbiológicos desse alimento, destinado ao consumo humano. No contexto exposto, o presente estudo foi elaborado de modo a avaliar a qualidade higiênico-sanitária de queijos produzidos e comercializados no Brasil.

\section{Metodologia}

\subsection{Caracterização do estudo}

O presente estudo se baseia em uma revisão sistemática de literatura, envolvendo um conjunto de pesquisas. Segundo Galvão e Pereira (2014, pág.183), a revisão sistemática "é um tipo de investigação focada em questão bem definida, que visa identificar, selecionar, avaliar e sintetizar as evidências relevantes disponíveis". Nessa concepção, essa modalidade de pesquisa segue padrões específicos e se constitui de um alto nível de evidência (Galvão \& Ricarte, 2020).

\subsection{Estratégia de busca}

Buscou-se por estudos publicados e indexados para a compilação dos artigos científicos sobre o tema sugerido neste trabalho nas bases de dados do Google Acadêmico, Periódico Capes e SciELO, sendo a coleta de dados realizada no período de junho a julho de 2021. Optou-se por artigos atuais e que foram publicados nas bases de dados supracitados no intervalo de tempo dos últimos sete anos, entre os anos 2014 e julho de 2021.

Vários termos foram utilizados nas buscas com o intuito de possibilitar uma maior coleta de dados para a pesquisa, dentre eles: "queijo", "avaliação microbiológica de queijos", "padrão microbiológico de queijos", "qualidade de queijos", "microbiological quality of cheeses", "microbiological profile of cheeses" e suas combinações nas línguas portuguesa e inglesa.

\subsection{Critérios, processo de seleção dos artigos e coleta de dados}

Foram utilizados, como critérios de seleção para a elaboração da revisão sistemática, artigos que abordassem a temática sugerida, parâmetro microbiológico de queijos produzidos e comercializados no Brasil, aplicando-se filtros de seleção que pudessem encontrar estudos direcionados ao tema em questão. Dessa forma, foram analisados os títulos, as palavras-chave, resumo e metodologia, assim como a leitura completa dos artigos selecionados para compor o presente estudo.

Como critérios de exclusão, foram descartados trabalhos sem relação direta com a temática da pesquisa, estudos duplicados nas bases de dados, monografias, dissertações, teses, artigos publicados em anais de eventos; artigos de revisão, capítulos de livros; e artigos com a data de publicação fora do intervalo de tempo sugerido (últimos sete anos, entre os anos 2014 a julho de 2021).

As buscas geraram um total de 592 artigos que foram avaliados pelo título e palavras-chave, resultando em 84 
estudos, os quais foram selecionados de acordo com a leitura do resumo e da metodologia. Como resultado, 50 artigos foram apreciados de acordo com a ideia central e as análises microbiológicas realizadas, e após a exclusão dos artigos, segundo os critérios supracitados, 23 artigos foram selecionados e analisados de maneira objetiva e criteriosa, sendo estes avaliados de forma integral, levando-se em consideração as informações apresentadas para compor a base para elaboração do presente artigo (Figura 1).

As principais informações dos estudos selecionados para esta revisão sistemática estão detalhadas no Quadro 1, identificados através dos códigos Q1 a Q23.

Figura 1- Processo de seleção dos artigos na revisão bibliográfica sistemática.

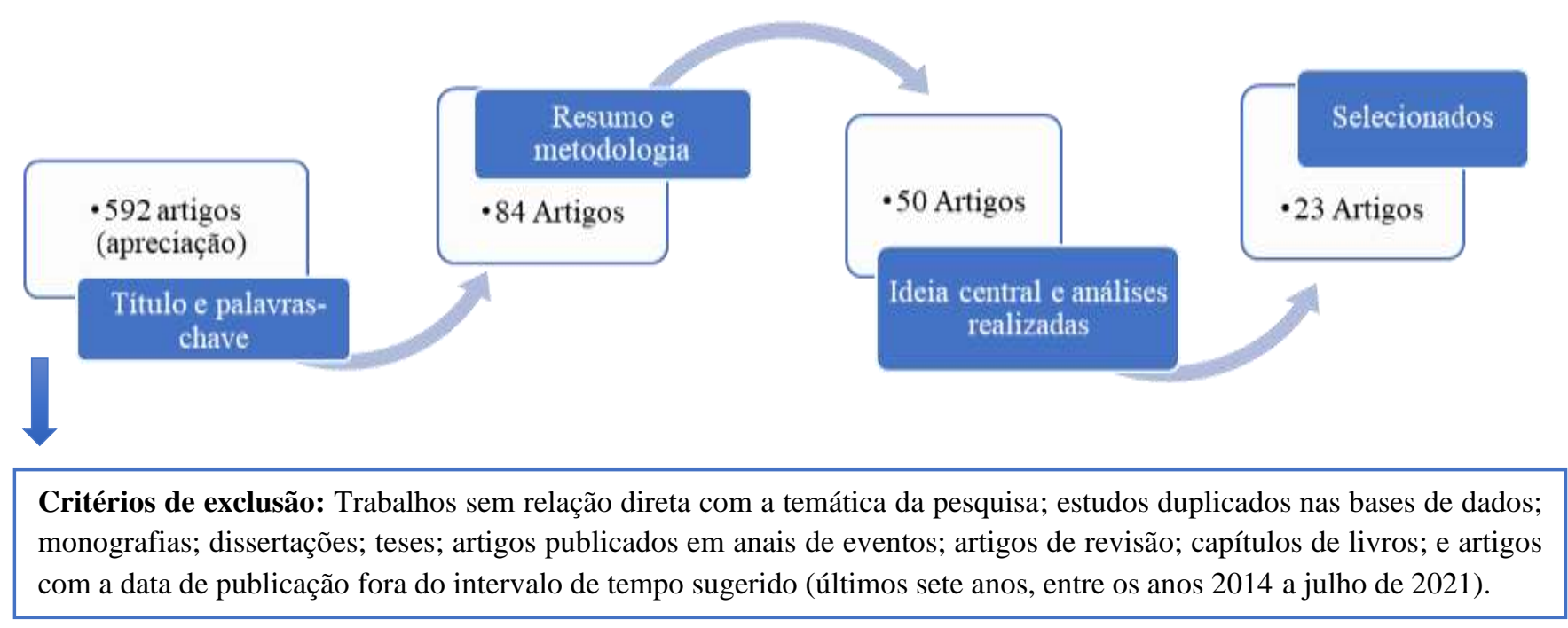

Fonte: Autores (2021).

Quadro 1 - Artigos selecionados nas bases de dados.

\begin{tabular}{|c|c|c|c|c|}
\hline \multicolumn{5}{|c|}{ Coleta de dados } \\
\hline ID & Título do Artigo & Análises realizadas & Base de Dados & Referência \\
\hline Q1 & $\begin{array}{l}\text { Análise microbiológica comparativa de queijo } \\
\text { coalho comercializado em supermercados e feiras } \\
\text { livres na Cidade de Maceió - Alagoas }\end{array}$ & 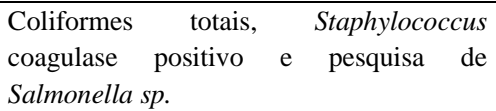 & $\begin{array}{c}\text { Google } \\
\text { acadêmico }\end{array}$ & $\begin{array}{l}\text { Munhoz et al. } \\
\text { (2021) }\end{array}$ \\
\hline Q2 & $\begin{array}{l}\text { Avaliação da contaminação por Staphylococcus } \\
\text { aureus em queijo coalho artesanal elaborado com } \\
\text { leite de cabra produzido no estado de Pernambuco }\end{array}$ & Contagem de Staphylococcus aureus. & SciELO & Aragão et al. (2020) \\
\hline Q3 & $\begin{array}{l}\text { Avaliação da qualidade de queijos de produção } \\
\text { informal }\end{array}$ & $\begin{array}{l}\text { Presença de Salmonella spp., } \\
\text { microrganismos psicrotróficos, limosidade } \\
\text { e bolor aparente. }\end{array}$ & $\begin{array}{l}\text { Periódicos } \\
\text { Capes }\end{array}$ & Amaral et al. (2020) \\
\hline Q4 & $\begin{array}{l}\text { Qualidade microbiológica de queijos tipo Minas } \\
\text { comercializados em Belo Horizonte, MG, Brasil }\end{array}$ & $\begin{array}{llll}\text { Contagem de coliformes } & \text { a } 45{ }^{\circ} \mathrm{C}, \\
\text { Staphylococcus coagulase } & \text { positiva } & \text { e } \\
\text { pesquisa de Salmonella sp. } & & \\
\end{array}$ & $\begin{array}{l}\text { Periódicos } \\
\text { Capes }\end{array}$ & Lopes et al. (2020) \\
\hline Q5 & $\begin{array}{l}\text { Qualidade microbiológica de queijos minas frescal } \\
\text { artesanais e industrializados }\end{array}$ & $\begin{array}{l}\text { Coliformes a } 35{ }^{\circ} \mathrm{C} \text {, coliformes a } 45^{\circ} \mathrm{C}, \\
\text { Estafilococos } \quad \text { coagulase positiva, } \\
\text { Salmonella sp. e Listeria monocytogenes. }\end{array}$ & $\begin{array}{l}\text { Periódicos } \\
\text { Capes }\end{array}$ & $\begin{array}{l}\text { Vilas Boas et al. } \\
\text { (2020) }\end{array}$ \\
\hline Q6 & $\begin{array}{l}\text { Qualidade microbiológica e caracterização da } \\
\text { resistência antimicrobianas de bactérias isoladas de } \\
\text { queijo coalho comercializados em Vitória da } \\
\text { Conquista - Bahia }\end{array}$ & $\begin{array}{l}\text { Coliformes totais e coliformes } \\
\text { termotolerantes, Staphylococcus coagulase } \\
\text { positivo, Escherichia coli, Listeria } \\
\text { monocytogenes e Salmonella spp. }\end{array}$ & $\begin{array}{l}\text { Periódicos } \\
\text { Capes }\end{array}$ & $\begin{array}{l}\text { Bomfim et al. } \\
\quad(2020)\end{array}$ \\
\hline
\end{tabular}




\begin{tabular}{|c|c|c|c|c|}
\hline Q7 & $\begin{array}{l}\text { Qualidade microbiológica de queijo minas frescal, } \\
\text { artesanal, comercializados em feiras livres do } \\
\text { Distrito Federal }\end{array}$ & $\begin{array}{l}\text { Coliformes totais, coliformes } \\
\text { termotolerantes e Salmonella sp. }\end{array}$ & $\begin{array}{l}\text { Periódicos } \\
\text { Capes }\end{array}$ & $\begin{array}{c}\text { Lima \& Cardoso } \\
\text { (2019) }\end{array}$ \\
\hline Q8 & $\begin{array}{l}\text { Microbiological quality of colonial cheese sold in } \\
\text { Porto Alegre-RS }\end{array}$ & $\begin{array}{l}\text { Coliformes a } 45^{\circ} \mathrm{C}, \text { Staphylococcus } \\
\text { coagulase positiva, Salmonella sp. e } \\
\text { Listeria monocytogenes. }\end{array}$ & $\begin{array}{l}\text { Periódicos } \\
\text { Capes }\end{array}$ & Ausani et al. (2019) \\
\hline Q9 & $\begin{array}{l}\text { Occurrence of Mycobacterium avium subsp. } \\
\text { paratuberculosis in coalho cheese in the State of } \\
\text { Pernambuco, Brazil }\end{array}$ & $\begin{array}{l}\text { Mycobacterium avium } \quad \text { subsp. } \\
\text { paratuberculosis (MAP). }\end{array}$ & SciELO & $\begin{array}{l}\text { Albuquerque } \text { et al. } \\
\qquad \text { (2019) }\end{array}$ \\
\hline Q10 & $\begin{array}{l}\text { Ocorrência de não conformidades físico-químicas e } \\
\text { microbiológicas em leite e derivados no estado de } \\
\text { Minas Gerais, no período de } 2011 \text { a } 2015\end{array}$ & $\begin{array}{l}\text { Coliformes totais e termotolerantes, } \\
\text { Listeria monocytogenes, Salmonella spp., } \\
\text { Staphylococcus coagulase positiva, } \\
\text { bolores e leveduras, e contagem de células } \\
\text { viáveis. }\end{array}$ & SciELO & Santos et al. (2019) \\
\hline Q11 & $\begin{array}{l}\text { Pseudomonas spp. and other psychrotrophic } \\
\text { microorganisms in inspected and non-inspected } \\
\text { Brazilian Minas Frescal cheese: proteolytic, } \\
\text { lipolytic and AprX production potentiall }\end{array}$ & $\begin{array}{llll}\text { Pseudomonas } & \text { spp. } & \text { e } & \text { bactérias } \\
\text { psicrotróficas. } & & & \\
\end{array}$ & SciELO & $\begin{array}{l}\text { Teider Junior et al. } \\
\text { (2019) }\end{array}$ \\
\hline Q12 & $\begin{array}{l}\text { Queijo artesanal produzido no sul do Rio Grande } \\
\text { do Sul: avaliação físico-química, microbiológica e } \\
\text { suscetibilidade a antimicrobianos de isolados de } \\
\text { staphylococcus coagulase positiva }\end{array}$ & $\begin{array}{l}\text { Contagem de Staphylococcus coagulase } \\
\text { positiva, coliformes termotolerantes, } \\
\text { pesquisa de Salmonella, Listeria } \\
\text { monocytogenes, isolamento de } \text { Yersinia } \\
\text { enterocolitica. }\end{array}$ & $\begin{array}{l}\text { Periódicos } \\
\text { Capes }\end{array}$ & Tavares et al. (2019) \\
\hline Q13 & $\begin{array}{l}\text { Análise sanitária e físico-química e adequação } \\
\text { bacteriológica do queijo minas artesanal produzido } \\
\text { em duas propriedades }\end{array}$ & $\begin{array}{l}\text { Coliformes totais, Escherichia coli, } \\
\text { Staphylococcus coagulase positivo, } \\
\text { Listeria monocytogenes e Salmonella spp. }\end{array}$ & SciELO & Soares et al. (2018) \\
\hline Q14 & $\begin{array}{l}\text { Avaliação microbiológica de queijo de coalho } \\
\text { comercializado na feira livre de Sousa - Paraíba }\end{array}$ & $\begin{array}{l}\text { Coliformes totais e termotolerantes, } \\
\text { Staphylococcus coagulase positivo e } \\
\text { Salmonella sp. }\end{array}$ & $\begin{array}{c}\text { Google } \\
\text { acadêmico }\end{array}$ & Bezerra et al. (2017) \\
\hline Q15 & $\begin{array}{l}\text { Hygienic-sanitary quality of Minas fresh cheese } \\
\text { sold in the city of Botucatu, São Paulo }\end{array}$ & 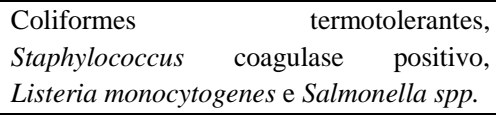 & SciELO & $\begin{array}{l}\text { Queiroz et al. } \\
\qquad(2017)\end{array}$ \\
\hline Q16 & $\begin{array}{l}\text { Qualidade microbiológica de queijo minas frescal } \\
\text { comercializado na zona da mata mineira }\end{array}$ & $\begin{array}{l}\text { Coliformes a } 35^{\circ} \mathrm{C} \text { e coliformes a } 45^{\circ} \mathrm{C} \text {, } \\
\text { Escherichia coli, Estafilococos coagulase } \\
\text { positiva, Staphylococcus aureus, Listeria } \\
\text { monocytogenes e Salmonella sp. }\end{array}$ & $\begin{array}{c}\text { Google } \\
\text { acadêmico }\end{array}$ & Souza et al. (2017) \\
\hline Q17 & $\begin{array}{l}\text { Qualidade microbiológica e físico-química do } \\
\text { queijo mussarela a granel comercializadas em Jataí } \\
\text { (Goiás, Brasil) }\end{array}$ & $\begin{array}{l}\text { Coliformes totais e termotolerantes, } \\
\text { Salmonella spp. e Staphylococcus spp. }\end{array}$ & $\begin{array}{c}\text { Google } \\
\text { acadêmico }\end{array}$ & Regis et al. (2017) \\
\hline Q18 & $\begin{array}{l}\text { Qualidade microbiológica de salames e queijos } \\
\text { coloniais produzidos e comercializados na região } \\
\text { sudoeste do Paraná }\end{array}$ & $\begin{array}{l}\text { Contagem de coliformes totais e } \\
\text { termotolerantes, Escherichia coli., } \\
\text { contagem de mesófilos aeróbios estritos e } \\
\text { facultativos, Staphylococcus coagulase } \\
\text { positiva e Salmonella sp. }\end{array}$ & $\begin{array}{l}\text { Periódicos } \\
\text { Capes }\end{array}$ & Casaril et al. (2017) \\
\hline Q19 & $\begin{array}{l}\text { Qualidade microbiológica e físico-química de } \\
\text { queijo minas frescal artesanal e industrial }\end{array}$ & $\begin{array}{l}\text { Presença de Salmonella spp, contagem de } \\
\text { Staphylococcus aureus, coliformes } \\
\text { termotolerantes e totais. }\end{array}$ & $\begin{array}{l}\text { Periódicos } \\
\text { Capes }\end{array}$ & Dias et al. (2016) \\
\hline Q20 & $\begin{array}{l}\text { Microbial quality of industrial and retail market } \\
\text { grated parmesan cheese in the State of São Paulo, } \\
\text { Brazil }\end{array}$ & $\begin{array}{ll}\text { Coliformes totais, termotolerantes e } & E . \\
\text { coli., contagem padrão de heterótrofos } \\
\text { mesofílicos, Salmonella spp., e } \\
\text { Staphylococcus coagulase positiva e } \\
\text { Staphylococcus aureus. }\end{array}$ & $\begin{array}{l}\text { Periódicos } \\
\text { Capes }\end{array}$ & Aguilar et al. (2016) \\
\hline Q21 & $\begin{array}{l}\text { Qualidade de queijos minas frescal produzidos e } \\
\text { comercializados informalmente em agroindústrias } \\
\text { familiares }\end{array}$ & $\begin{array}{l}\text { Coliformes a } 35^{\circ} \mathrm{C} \text { e coliformes a } 45^{\circ} \mathrm{C}, \\
\text { Staphylococcus coagulase positiva, } \\
\text { Salmonella sp. e Listeria monocytogenes. }\end{array}$ & $\begin{array}{l}\text { Periódicos } \\
\text { Capes }\end{array}$ & Vinha et al. (2016) \\
\hline Q22 & $\begin{array}{l}\text { Aspectos físico-químicos e microbiológicos do } \\
\text { queijo tipo coalho comercializado em estados do } \\
\text { nordeste do Brasil }\end{array}$ & $\begin{array}{l}\text { Coliformes a } 45^{\circ} \mathrm{C}, \text { Samonella } \\
\text { Staphylococcus coagulase positiva. }\end{array}$ & SciELO & Sousa et al. (2014) \\
\hline Q23 & $\begin{array}{l}\text { Avaliação da qualidade microbiológica do Queijo } \\
\text { minas frescal produzido por Laticínios do estado de } \\
\text { Minas Gerais }\end{array}$ & $\begin{array}{l}\text { Coliformes totais e termotolerantes, } \\
\text { Estafilococos coagulase positiva, } \\
\text { Salmonela spp. e Listeria monocytogenes. }\end{array}$ & $\begin{array}{l}\text { Periódicos } \\
\text { Capes }\end{array}$ & $\begin{array}{l}\text { Apolinário et al. } \\
\text { (2014) }\end{array}$ \\
\hline
\end{tabular}

Fonte: Autores (2021). 


\section{Resultados e Discussão}

\subsection{Padrão microbiológico de queijo coalho}

A respeito do padrão microbiológico do queijo coalho, ressaltamos que, na pesquisa de Munhoz et al. (2021), identificada como Q1, 24 amostras de queijo coalho (sendo 12 amostras industrializadas e 12 amostras artesanais, comercializados em supermercados e feiras livres no município de Maceió - AL) não se enquadraram dentro dos padrões de qualidade microbiológica analisados, apresentando parâmetros de coliformes totais, Staphylococcus coagulase positivo e pesquisa de Salmonella sp. acima do permitido pela legislação vigente. Das amostras de queijo industrializado, 33\% apresentaram valores elevados para coliformes totais e metade $(50 \%)$ das amostras apresentaram valores positivos para a contagem de Staphylococcus coagulase positivo, refletindo a deficiência na qualidade higiênica no processamento desses alimentos.

Resultados negativos foram evidenciados quanto à presença de Salmonella sp. em todas as amostras avaliadas, exceto em uma delas. Ainda segundo o estudo, 58,3\% das amostras de queijo artesanal apresentaram valores elevados quanto à presença de coliformes totais, 33,5\% das amostras apresentaram valores positivos para a contagem de Staphylococcus coagulase positivo e $25 \%$ apresentaram valores positivos para Salmonella sp., o que inviabiliza o consumo desse produto. Com base nos resultados obtidos neste estudo, é possível considerar que as amostras apresentaram uma alta contaminação por Salmonella sp., indicando uma grave falha na produção e qualidade da higiene durante a elaboração do queijo, aspecto que é reafirmado com a grande presença de Staphylococcus coagulase positivo, muito acima do que a legislação vigente permite, tornando o produto impróprio para o consumo.

No tocante ao estudo de Aragão et al. (2020), identificado como Q2, que avaliou o nível de contaminação por Staphylococcus aureus em 30 amostras de queijo coalho artesanal produzidos com leite de cabra cru de 11 municípios do estado de Pernambuco, é possível pontuar, segundo os dados da pesquisa, que 100,0\% das amostras analisadas apresentaram crescimento de colônias típicas de S. aureus; assim, todas as amostras estavam fora dos padrões exigidos pela legislação, sendo consideradas inadequadas para o consumo. Dos 11 municípios estudados, 81,8\% apresentaram pelo menos uma amostra contaminada pelo microrganismo em estudo, o que sugere falha na aplicação das Boas Práticas de Fabricação desse produto, fator que reflete, de maneira negativa, diretamente nas suas condições higiênico-sanitárias. Portanto, sendo um microrganismo majoritariamente proveniente da pele humana, pode-se deduzir um grave erro na manipulação do produto.

Bomfim et al. (2020) destaca em sua pesquisa, identificada como Q6, a qualidade higiênico-sanitária de 20 amostras de queijo coalho adquiridos em duas feiras livres, no município de Vitória da Conquista, Bahia, através das análises de coliformes totais e termotolerantes, Staphylococcus coagulase positivo, Escherichia coli, Listeria monocytogenes e Salmonella spp. Segundo os resultados do trabalho, $100 \%$ das amostras analisadas apresentaram contagens acima do permitido pela legislação para coliformes totais, das quais $62,5 \%$ foram positivas para coliformes termotolerantes com confirmação para $E$. coli., estando fora dos padrões exigidos para o consumo. Ressalta-se também que 91,66\% das amostras analisadas foram positivas para a presença de Staphylococcus coagulase positivo, sendo que, em $87,5 \%$, essa contagem foi acima do permitido pela legislação, fator que é de suma importância, tendo em vista a termoresistência das entorotoxinas produzidas pelo $S$. aureus, indicando um elevado grau de contaminação, tornando todas as amostras impróprias para o consumo. Não foram detectadas nas amostras do estudo a presença de Listeria monocytogenes e Salmonella spp.

Ao analisar o trabalho de Bezerra et al. (2017), identificado como Q14, verificamos que o autor avaliou a qualidade microbiológica de 20 amostras de queijo coalho comercializadas em uma feira livre do município de Sousa-PB. Na pesquisa, foram avaliados parâmetros como: coliformes totais e termotolerantes, Staphylococcus coagulase positivo e Salmonella sp. De acordo com os valores obtidos para coliformes totais, é possível observar que, do total de amostras analisadas, somente uma apresentou contagens elevadas para esse microrganismo. Em relação aos coliformes termotolerantes, 35\% das amostras 
apresentaram contagens acima do permitido pela legislação, o que denota práticas ineficientes de higiene durante o processo. Salienta-se ainda que, das 20 amostras analisadas, 13 (65\%) apresentaram valores positivos para a contagem de Staphylococcus coagulase positivo e oito (40\%) para o crescimento de Salmonella sp., aspecto que reflete a necessidade de aperfeiçoamento no processamento, armazenamento e distribuição dos queijos.

A pesquisa de Albuquerque et al. (2019), identificada como Q9, investigou a presença do microrganismo Mycobacterium avium subsp. paratuberculosis (MAP) em 40 amostras de queijo coalho artesanal adquiridas em estabelecimentos comerciais do estado de Pernambuco. Esse microrganismo, por sua vez, é patógeno encontrado em ruminantes. Para tanto, sua presença nas amostras indica uma falha sistêmica no processo de elaboração do queijo. Para esta análise, foi utilizada a técnica de Reação em Cadeia da Polimerase em Tempo Real (qPCR) para detecção da região IS900 do MAP. Assim, das 40 amostras analisadas, 11 (27,5\%) se mostraram positivas para a região IS900 do MAP, indicando que esse produto se constitui como uma fonte de exposição humana a essa bactéria, uma vez que, como já mencionado aqui, é um patógeno originário de ruminantes. No entanto, os autores sugerem mais pesquisas que possam ser realizadas na área para determinar a viabilidade desse microrganismo no objeto de estudo, já que este pode estar associado a vários tipos de enfermidades em humanos, e a sua presença em 40 amostras indica uma correlação incomum no processo produtivo, haja vista que não é um microrganismo frequente de ser encontrado em tantas amostras, fator que alerta para a necessidade de ser melhor investigado, sobretudo, porque ele se configura como um grave risco à saúde do consumidor.

Quanto às análises de Sousa et al. (2014), identificadas como Q22, estas avaliaram em sua pesquisa o perfil microbiológico de 104 amostras de queijo coalho, comercializadas nos estados de Pernambuco, Piauí, Ceará, Rio Grande do Norte, Sergipe e Paraíba, sendo 50 amostras sobre o registro de inspeção estadual (SIE) e federal (SIF), e 54 sem inspeção. A análise se deu através da verificação de Número Mais Provável (NMP) de coliformes a 45도. Samonella sp. e Staphylococcus coagulase positiva. Conforme os resultados obtidos, $100(96,15 \%)$ amostras analisadas estavam fora dos limites aceitos pela legislação para Staphylococcus coagulase positiva, 32 amostras (31\%) para coliformes termotolerantes e uma amostra para a presença de Salmonella sp., não havendo diferenças significativas entre as amostras com e sem inspeção para as análises microbiológicas, o que sugere falhas na aplicação das Boas Práticas de Fabricação e na fiscalização dos produtos pelas entidades competentes.

\subsection{Padrão microbiológico de queijo minas frescal e padrão}

No que se refere às pesquisas de Soares et al. (2018), sobre o padrão microbiológico do queijo minas frescal, identificadas como Q13, analisaram-se nesse estudo amostras de queijo minas artesanal de duas propriedades rurais, com o intuito de descrever as condições higiênico-sanitárias de queijarias artesanais em Uberlândia-MG, de modo a determinar os parâmetros bacteriológicos através das análises de coliformes totais, Escherichia coli, Staphylococcus coagulase positivo, Listeria monocytogenes e Salmonella spp. nesse produto. Segundo a pesquisa, nenhuma das amostras analisadas apresentou a incidência de Listeria monocytogenes e somente uma obteve o resultado positivo para Salmonella spp., o que inviabiliza o consumo deste produto por não possuir qualidade microbiológica.

Sobre a contagem de coliformes totais e E. coli, foi constatado nesse estudo, após o treinamento e implantação das Boas Práticas dos produtores, que elas diminuíram significativamente nos queijos fabricados, indicando que a contaminação do produto é consequência da contaminação inicial da matéria-prima e da manipulação do produto, o que torna necessário atentar para a sanidade do rebanho e para a capacitação frequente dos manipuladores.

A pesquisa de Vilas Boas et al. (2020), identificada como Q5, destaca em trabalho realizado com 30 amostras de queijos minas frescal (15 amostras de cinco industriais e 15 artesanais), comercializados no sul de Minas Gerais, que as amostras de queijos industriais apresentaram uma melhor qualidade higiênico-sanitária frente às amostras artesanais, estando 
estas dentro dos padrões exigidos pela legislação quando analisados os parâmetros de coliformes a $35{ }^{\circ} \mathrm{C}$, coliformes a $45^{\circ} \mathrm{C}$, Estafilococos coagulase positiva, Salmonella sp. e Listeria monocytogenes. Ainda nessa pesquisa, foi identificada a presença da Salmonella sp. em $60 \%$ das amostras, sendo possível confirmar a presença da Salmonella typhimurium em uma das amostras analisadas. Além disso, altas contagens de coliformes a $35^{\circ} \mathrm{C}$ foram identificadas em todas as amostras. Das 15 amostras de queijos artesanais, $20 \%$ apresentaram coliformes termotolerantes acima dos limites toleráveis pela legislação vigente, sendo confirmada a presença de E. coli em amostras de dois produtores rurais, o que significa que as medidas de higiene não foram rigorosamente adotadas. $80 \%$ das amostras provenientes de produtores artesanais foram positivas para a presença de Estafilococos coagulase positiva, não sendo detectada em nenhuma das 30 amostras analisadas a presença de Listeria Monocytogenes.

Na pesquisa de Queiroz et al. (2017), identificada como Q15, verificou-se a qualidade higiênico-sanitária através das análises microbiológicas de coliformes termotolerantes, Staphylococcus coagulase positivo, Listeria monocytogenes e Salmonella spp. de 50 queijos do tipo minas frescal em datas próximas à sua fabricação e datas próximas à validade do produto, comercializados na cidade de Botucatu, São Paulo. Além disso, cepas de S. aureus foram submetidas à pesquisa de genes codificadores de produção de enterotoxinas clássicas e, também, sua produção in vitro. Nesse trabalho, foram verificados resultados acima do permitido pela legislação para coliformes termotolerantes em $36 \%$ das amostras durante a primeira análise e em $44 \%$ para a segunda análise. Para a contagem de Staphylococcus coagulase positivo, $10 \%$ das amostras de queijos na data de produção estavam fora do padrão estabelecido, como também 14\% das amostras que estavam próximas à data de validade. A presença de Listeria monocytogenes e Salmonella spp. foi constatada na amostra com a data de expiração da validade e na amostra próxima à data de produção, respectivamente, o que implica na ausência da aplicação de práticas de higiene sanitária e inadequações quanto à temperatura de comercialização.

Mesmo após todo o processo de maturação do queijo, os índices de contaminação continuaram elevados, mantendo-se uma faixa relativamente estável, apesar da variação de $\mathrm{pH}$ entre o produto novo e o pH mais baixo do produto próximo à sua data de vencimento, evidenciando uma alta carga microbiana oriunda de condições precárias de higiene durante o processo. Constatou-se, também, durante os estudos in vitro, que três cepas de $S$. aureus. produziram duas enterotoxinas estafilocócicas, sendo elas Staphylococcal Enterotoxin B (SEB) e Staphylococcal Enterotoxin C (SEC), o que implica em seu potencial para causar intoxicação e colocar em risco a saúde dos consumidores através da disseminação de surtos alimentares. Considerando estes achados da pesquisa, os autores ressaltam a importância do armazenamento apropriado para esse tipo de alimento, uma vez que o armazenamento em temperatura inapropriada acelera a produção destas enterotoxinas, pelos microrganismos, fazendo com que o produto tenha um grau elevado de toxicidade, além da contaminação em si.

Ao aprofundarmo-nos no trabalho desenvolvido por Santos et al. (2019), identificado como Q10, foram diagnosticadas, por meio da avaliação de dados oficiais, ocorrências de divergências microbiológicas em vários produtos lácteos produzidos em indústrias registradas no Instituto Mineiro de Agropecuária. Foram analisadas, na pesquisa, 423 amostras de queijo minas frescal e 224 amostras de queijo minas padrão, utilizando-se de análises microbiológicas de coliformes totais e coliformes termotolerantes, Listeria monocytogenes, Salmonella spp., Staphylococcus coagulase positiva, bolores e leveduras, e contagem de células viáveis. Confere-se que os coliformes a $35^{\circ} \mathrm{C}$ e os termotolerantes a $45^{\circ} \mathrm{C}$ apresentaram valores elevados nas amostras analisadas de queijo minas frescal, representando um total de 66 e 30 amostras em desacordo com a legislação, respectivamente. Altas contagens de coliformes a $35^{\circ} \mathrm{C}$ e os termotolerantes a $45^{\circ} \mathrm{C}$ indicam condições precárias de manipulação e fabricação do produto, uma vez que esses microrganismos são indicadores da qualidade higiênico-sanitária de alimentos. O número de amostras contaminadas por bolores e leveduras totalizou 187, para Staphylococcus coagulase positiva verificou-se 118, para Salmonella spp., 1, para teor de proteína, 164 amostras de produtos estavam em desacordo com os padrões ideais. Para as amostras de queijo minas padrão, 14 amostras não apresentaram 
conformidade para Staphylococcus coagulase positiva, o que demonstra a falta de higiene por parte dos manipuladores no processo.

No estudo de Teider Junior et al. (2019), identificado como Q11, foram analisadas 20 amostras de queijo minas frescal, 10 amostras inspecionadas e 10 amostras não inspecionadas para parâmetros como Pseudomonas spp. e outras bactérias psicrotróficas, avaliando seu potencial lipolítico, proteolítico e de produção de metaloprotease alcalina. Com base nos resultados obtidos, as condições de produção das amostras de queijos analisadas não foram suficientes para controlar o desenvolvimento de Pseudomonas spp. e outras bactérias psicrotróficas, indicando a necessidade de medidas mais rígidas de higiene durante o processo de fabricação deste produto, já que a presença desses microrganismos pode ser controlada com o processo de pasteurização e o armazenamento apropriado.

A pesquisa de Souza et al. (2017), identificada como Q16, utilizou 50 amostras de queijo minas frescal, sendo 43 amostras oriundas do setor industrial e 7 amostras advindas de processos artesanais de seis municípios da Zona da Mata Mineira. Para a determinação da qualidade microbiológica dos produtos analisados foram utilizadas as análises de coliformes a $35^{\circ} \mathrm{C}$ e a $45^{\circ} \mathrm{C}$, Escherichia coli, Estafilococos coagulase positiva, Staphylococcus aureus, Listeria monocytogenes e Salmonella sp. Nesse estudo, foi constatado que, independentemente de sua origem, todas as amostras foram positivas para coliformes a $35^{\circ} \mathrm{C}$. Das 50 amostras analisadas, $40 \%$ (20 amostras) excederam o limite máximo para a contagem de coliformes a $45^{\circ} \mathrm{C}$, sendo 15 de fabricação industrial e 5 artesanal. A presença de E. coli. foi confirmada em 16 amostras (32\%), sendo a maioria delas de produção artesanal, o que reflete a ausência de Boas Práticas de Fabricação durante a elaboração do produto, já que a presença deste microrganismo sugere contaminação fecal no alimento.

Em relação às contagens de Estafilococos coagulase positiva, 16 (32\%) amostras estavam acima do limite permitido e 10 (20\%) continham S. aureus, o que gera preocupação, uma vez que esse microrganismo é responsável pelo desenvolvimento de enterotoxina promotora de intoxicações em humanos. Não foi evidenciada a presença de Listeria monocytogenes nas amostras em estudo, no entanto, 20 (40\%) delas foram positivas para Salmonella sp., evidenciando a necessidade da adoção de técnicas apropriadas de produção, processamento e armazenamento do produto.

No trabalho de Lopes et al. (2020), identificado como Q4, a qualidade microbiológica de queijos minas industrializados e artesanais comercializados em Belo Horizonte, MG, foi avaliada por meio da contagem de coliformes a 45 ${ }^{\circ} \mathrm{C}$, Staphylococcus coagulase positiva e pesquisa de Salmonella sp. No estudo, foram analisadas 18 amostras de queijos, sendo 9 industrializados e 9 artesanais. Segundo os resultados obtidos, duas amostras de queijos minas industrializados apresentaram contagens acima do permitido pela legislação para coliformes a $45{ }^{\circ} \mathrm{C}$ e quatro amostras do queijo artesanal estavam em desacordo com os limites de tolerância. 100\% das amostras, independente da origem, apresentaram contagens superiores para Staphylococcus coagulase positiva, não apresentando, porém, contaminação por Salmonella sp., resultando, dessa forma, em $100 \%$ das amostras inapropriadas para o consumo.

Dias et al. (2016), trabalho identificado como Q19, desenvolveu um estudo no qual analisou as condições higiênico sanitárias quanto à presença de Salmonella spp., contagem de Staphylococcus aureus, de coliformes termotolerantes e totais de queijos minas frescal na região sul do estado de Goiás, analisando a presença de Salmonella spp., contagem de Staphylococcus aureus, de coliformes termotolerantes e totais. Foram utilizadas no estudo 10 amostras de queijo, sendo 5 de queijos produzidos industrialmente e 5 de forma artesanal. Verificou-se, a partir dos estudos, que todas as amostras analisadas foram positivas para coliformes termotolerantes e totais, em que $5(50 \%)$ das amostras industrializadas apresentaram limites acima do estabelecido para coliformes termotolerantes, indicando falhas no processo de pasteurização do leite, e duas amostras artesanais (20\%) estavam em desacordo com os padrões estabelecidos. Observou-se, também, que todas as amostras (100\%) estavam fora do padrão estabelecido pela legislação no que se refere ao parâmetro de coliformes totais, o que sinaliza falhas no processamento térmico e nas práticas de higiene dos manipuladores. Em relação à contagem de Staphylococcus aureus, apenas 
três $(30 \%)$ das amostras apresentaram-se de acordo com o limite permitido. Todas as amostras analisadas, independente da origem, revelaram ausência de Salmonella spp.

Ao analisar a qualidade microbiológica de 30 amostras de queijos de produção informal sem inspeção sanitária, comercializados em feiras livres no Distrito Federal, através das análises de presença de Salmonella spp., de microrganismos psicrotróficos e desenvolvimento de limosidade e bolor aparente, Amaral et al. (2020), identificado como Q3, constatou a partir dos resultados obtidos altos índices de microrganismos psicrotróficos e presença de limosidade na superfície de $40 \%$ das amostras. Foi examinada também a presença de bolores em 10 amostras (33,3\%), sendo que em 7 (23,3\%) destas o aparecimento dos bolores foi concomitante com o desenvolvimento de limosidade, fatores estes que são indesejáveis e que refletem interferências na qualidade e na vida de prateleira do produto, o que também indica problemas com o armazenamento do produto.

No trabalho de Lima e Cardoso (2019), identificado como Q7, o perfil microbiológico de 20 amostras de queijos minas frescal, feitos artesanalmente, vendidos em feiras livres do Distrito Federal, foi determinado através das análises de coliformes totais, termotolerantes e Salmonella sp. De acordo com os resultados obtidos, $100 \%$ das amostras analisadas apresentaram contaminação por coliformes totais e termotolerantes e $95 \%$ foram positivas para a presença de Salmonella sp., o que sugere falhas durante o processamento desse alimento, seja em relação ao uso da matéria-prima, má higiene dos utensílios e local inapropriado, dentre outros fatores. Das 20 amostras analisadas, 100\% apresentaram-se impróprias para o consumo.

A pesquisa de Vinha et al. (2016), identificada como Q21, analisou 77 amostras de queijos minas frescal, 39 coletadas na fonte de produção e 38 nos pontos de venda, oriundos de agroindústrias informais no município de Viçosa, Minas Gerais. Das agroindústrias que participaram da pesquisa, três produziam o produto com leite pasteurizado e outras três utilizavam leite cru. Foi traçado o perfil microbiológico e sanitário dos produtos através das análises de coliformes a $35^{\circ} \mathrm{C}$ e coliformes a $45^{\circ} \mathrm{C}$, Staphylococcus coagulase positiva, Salmonella sp. e Listeria monocytogenes. Segundo os resultados, a qualidade higiênicosanitária das amostras analisadas foi insatisfatória, uma vez que foram constatados altos índices de coliformes totais e termotolerantes, sendo as amostras coletadas no comércio as que apresentaram maiores valores para esses parâmetros, refletindo a falta de higiene durante o processamento do produto. Além disso, a contagem de Staphylococcus coagulase positiva também foi constatada em níveis superiores aos permitidos pela legislação, em que os queijos produzidos com leite cru foram os que apresentaram percentuais maiores.

$\mathrm{Na}$ análise em questão, não foi constatada a presença de Salmonella sp. em nenhuma das amostras analisadas, no entanto, foi constatada a presença de Listeria monocytogenes em uma das amostras oriundas de uma agroindústria que utilizava leite pasteurizado na fabricação do queijo. Esse resultado denota falha no controle no binômio tempo/temperatura e, consequentemente, acarreta a contaminação do produto, inviabilizando seu consumo por colocar em risco a saúde do consumidor.

Cabe destacar, ainda, a pesquisa de Apolinário et al. (2014), identificada como Q23, que apresentou em seus escritos a inviabilidade do consumo de amostras de queijos produzidos por diferentes indústrias da região da Zona da Mata Mineira, as quais foram fiscalizadas por Serviços de Inspeção Federal, Estadual e Municipal por apresentarem qualidade microbiológica insatisfatória, o que compromete a segurança do alimento para o consumidor. No referido trabalho, foram analisadas 31 amostras de queijos minas frescal para os parâmetros microbiológicos de coliformes totais, coliformes termotolerantes, Estafilococos coagulase positiva, Salmonela spp., e Listeria monocytogenes. Considerando os resultados, 77,4\% das amostras apresentaram valores acima dos recomendados para coliformes totais, e 17 amostras $(54,8 \%)$ para coliformes termotolerantes. Em relação à contagem de Estafilococos coagulase positiva, 16,12\% das amostras estavam acima do limite permitido pela legislação, bem como, observou-se a presença de Listeria monocytogenes em 9,6\% das amostras. Não foi constatada a presença de Salmonella sp. em nenhuma das amostras analisadas. Contudo, os dados obtidos revelaram que as amostras não 
apresentavam qualidade microbiológica satisfatória, fator que compromete a saúde dos consumidores.

\subsection{Padrão microbiológico de queijo colonial}

A respeito do padrão microbiológico do queijo colonial, destacamos a pesquisa de Tavares et al. (2019), identificada como Q12, na qual verificou-se a qualidade microbiológica de queijos coloniais produzidos artesanalmente e comercializados na região sul do Rio Grande do Sul. Nesse estudo, foram analisadas 30 amostras de queijo do mercado local e de feiras livres. Para traçar o perfil microbiológico, foram realizadas as análises microbiológicas de contagem de Staphylococcus coagulase positiva, contagem de coliformes termotolerantes, pesquisa de Salmonella e Listeria monocytogenes, além do isolamento do Yersinia enterocolitica.

Observando os levantamentos do estudo, avaliou-se que 24 (80\%) das amostras apresentaram contagens de Staphylococcus coagulase positiva acima do permitido e 13 (43,33\%) estavam acima do estabelecido para coliformes termotolerantes, no entanto, todas as amostras se revelaram negativas para a presença de Salmonella spp. e Listeria monocytogenes. Quanto ao isolamento de Yersinia enterocolitica, foi possível confirmar a presença da bactéria em uma das amostras $(3,33 \%)$. Os resultados corroboram uma alta contaminação microbiana nos produtos analisados, podendo estes causar danos à saúde do consumidor.

No estudo de Ausani et al. (2019), identificado como Q8, foi analisado na cidade de Porto Alegre o perfil microbiológico de queijos coloniais comercializados em feiras livres e mercado municipal. Foram examinadas 205 amostras de queijo, compreendendo 17 marcas distintas, para as análises microbiológicas de coliformes a $45^{\circ} \mathrm{C}$, Staphylococcus coagulase positiva, Salmonella sp. e Listeria monocytogenes. Em avaliação, levantou-se que 10,73\% das amostras foram positivas para coliformes a $45^{\circ} \mathrm{C}$ e $40,48 \%$ para Staphylococcus coagulase positiva, em que os valores obtidos foram superiores ao estabelecido na legislação vigente. $2,9 \%$ das amostras foram positivas para a presença de L. monocytogenes, não sendo detectada a presença de Salmonella sp., o que sugere a necessidade de um acompanhamento mais efetivo da fiscalização para esses produtos quanto ao cumprimento das Boas Práticas de Fabricação.

No trabalho de Casaril et al. (2017), identificado como Q18, a qualidade higiênico-sanitária de 10 amostras de queijo colonial (produtos inspecionados e sem o selo de inspeção sanitária) produzidos e comercializados na região sudoeste do Paraná, foram selecionados para as análises de contagem de coliformes totais e termotolerantes, Escherichia coli., contagem de mesófilos aeróbios estritos e facultativos, Staphylococcus coagulase positiva e Salmonella sp. Ao examinarmos os resultados alcançados, é possível pontuar que altas contagens de mesófilos aeróbios estritos e facultativos foram constatados nas amostras em estudo. Além disso, $70 \%$ das amostras analisadas foram positivas para a contagem de coliformes totais e 50\% não atenderam à legislação vigente quanto à contagem de coliformes termotolerantes. No que diz respeito à contagem de E. coli, quatro amostras foram positivas para esse microrganismo e uma amostra indicou presença de Salmonella sp., demonstrando que o produto estava fora dos padrões exigidos pela legislação para o consumo e, consequentemente, apresentando risco potencial à saúde do consumidor.

\subsection{Padrão microbiológico de queijo muçarela e parmesão}

Sobre o padrão microbiológico de queijos muçarela e parmesão, evidenciamos a pesquisa de Regis et al. (2017), identificada como Q17, na qual foi avaliada a qualidade microbiológica do queijo muçarela comercializado a granel no município de Jataí (GO). Para a análise, foram coletadas 10 amostras de queijo de diferentes marcas em comércios locais. Para avaliar a qualidade microbiológica dos produtos, foram utilizadas as análises de coliformes totais e termotolerantes, Salmonella spp. e contagem da Unidade de Formadora de Colônia (UFC) de Staphylococcus spp. A partir dos dados obtidos na pesquisa, infere-se que $20 \%$ das amostras analisadas foram positivas para Salmonella spp. Em relação à contagem de Staphylococcus 
aureus e coliformes totais, $40 \%$ e $20 \%$ das amostras estudadas apresentaram resultados positivos para esses microrganismos, respectivamente, o que enfatiza a importância do cumprimento de normas referentes às Boas Práticas de Fabricação.

Em Santos et al. (2019), identificado como Q10, nos é apresentada uma pesquisa sobre a ocorrência de não conformidades microbiológicas em vários produtos lácteos produzidos em indústrias registradas no Instituto Mineiro de Agropecuária. Para esse trabalho, foram selecionadas e examinadas 1.816 amostras de queijo muçarela, as quais foram submetidas às análises microbiológicas de coliformes totais e coliformes termotolerantes, Listeria monocytogenes, Salmonella spp., Staphylococcus coagulase positiva, bolores e leveduras e contagem de células viáveis. Desse total, 132 amostras apresentaram não conformidade quanto aos parâmetros microbiológicos analisados, 9 foram positivas para coliformes totais, 33 para coliformes termotolerantes, 10 para bolores e leveduras e 80 para Staphylococcus coagulase positiva. Não foi evidenciada a presença de Listeria monocytogenes nas amostras em estudo, assim como também de Salmonella spp. e mesófilos.

A pesquisa de Aguilar et al. (2016), identificada como Q20, objetivou avaliar as condições higiênico-sanitárias de queijos tipo parmesão ralados, vendidos no comércio varejista, no município de Ribeirão Preto, estado de São Paulo. Foram analisadas 120 amostras, das quais 60 eram de quatro marcas que comercializaram o produto ralado industrialmente e outras 60 pertenciam a quatro marcas em que os produtos eram adquiridos pelos comércios varejistas em grandes peças e ralados no ato da venda. No estudo, foram avaliados parâmetros como coliformes totais, termotolerantes e E. coli., contagem padrão de heterótrofos mesofílicos, Salmonella spp., e contagem de Staphylococcus coagulase positiva e Staphylococcus aureus. As amostras de queijo ralado industrialmente apresentaram um menor percentual, em relação ao queijo ralado no momento da venda para coliformes totais, termotolerante e E. coli., embora as quantidades apresentadas estivessem dentro dos limites estabelecidos pela legislação. As populações de microrganismos heterotróficos mesófilos variaram, mas acabam por fornecer informações às características sanitárias do produto em estudo.

Foi constatada, também, a presença Staphylococcus spp. em todas as amostras analisadas, sendo que 60,0\% dessas apresentaram Staphylococcus coagulase positivo e 52,5\% delas com populações acima do limite permitido pela legislação. Além disso, 57,5\% das amostras foram positivas para a presença de Staphylococcus aureus, no entanto, Salmonella spp. não foi isolada de nenhuma amostra. A partir dos resultados, pode-se verificar uma melhor qualidade microbiológica nos queijos ralados industrialmente em face de condições higiênico-sanitárias mais satisfatórias. Observou-se ainda, nessa pesquisa, que se torna fundamental salientar que a cadeia de produção de queijos e a manutenção da correlação entre as boas práticas de higiene, juntamente com o manuseio correto da matéria-prima e a aplicação das normas sanitárias, mostram-se como fatores determinantes para se alcançar uma menor carga microbiológica.

Dessa forma, verifica-se que no processo de fabricação da cadeia de queijos em muitas realidades pode ser priorizado o modo artesanal, uma vez que a história e a cultura exercem influência sobre este aspecto. Assim, algumas superstições estão atreladas à sua produção, principalmente entre os pequenos produtores, os quais acreditam que a antiga metodologia de produção é a principal responsável pela qualidade do queijo, proporcionando um sabor, uma textura e um aroma característicos.

Com efeito, muitas vezes, a tradição prevalece em detrimento das boas práticas de higiene, e ambas não precisam ser consideradas antagonistas, visto que elas se complementam, tal como demonstra a indústria em maior escala. Alguns pequenos produtores fabricam usando utensílios de madeiras como, por exemplo, as prensas e formas, que atreladas às condições higiênico-sanitárias do manuseio da ordenha do leite, dificultam o processo de higienização. Outro fator que corrobora para que haja contaminação microbiológica é a maneira incorreta do armazenamento do produto acabado, como a temperatura de estocagem. Assim, observa-se que a adoção e aplicação efetiva das boas práticas de higiene aliadas à correta manipulação do produto, cujo processo envolve desde a manipulação da matéria-prima até a finalização do produto, são ações de extrema 
importância para a segurança alimentar, como também para prevenir a contaminação cruzada ou diversos outros tipos de contaminação bacteriana.

Com base nos trabalhos analisados, destaca-se a eficiência da implementação de práticas higiênico-sanitárias na cadeia de produção de queijos como fator decisivo na redução das doenças veiculadas pelos alimentos, provocadas por agentes biológicos responsáveis pelos surtos alimentares. Acrescenta-se, ainda, que os agentes externos patogênicos à flora bacteriana normal do queijo têm sido apontados como os responsáveis por muitas doenças de origem alimentar. Isso reforça a necessidade de implementação de práticas sanitárias para que o produto possa ser considerado apto para o consumo e, dessa forma, garantir a saúde do consumir.

\section{Conclusão}

A partir das análises realizadas, constatou-se que os parâmetros microbiológicos possuem direta correlação com as boas práticas de higiene, juntamente com o manuseio correto da matéria-prima e a aplicação das normas sanitárias, que contribuem para uma menor carga microbiológica presente nas amostras.

As pesquisas também comprovam que a eficiência da implantação das boas práticas de fabricação contribui para uma redução dos riscos de surtos alimentares. Contudo, para garantir a inocuidade do produto, é necessário um conjunto de ações que incluem reforço e repetição dos treinamentos, registro das atividades, rastreabilidade, associadas ao monitoramento e fiscalização regular dos produtos comercializados.

Vale salientar que, das amostras de queijos analisadas nos referidos estudos, praticamente todas apresentaram condições inapropriadas para o consumo humano devido à ausência de higiene sanitária e inadequações quanto ao armazenamento e comercialização desses produtos, o que pode ser constatado a partir dos parâmetros microbiológicos analisados.

Assim, considera-se de fundamental importância a atuação dos órgãos de serviços de saúde e vigilância sanitária no tocante ao desenvolvimento de ações e projetos educacionais na área de alimentos que visem o estabelecimento de melhorias no beneficiamento da matéria-prima, no processo de produção, armazenamento e comercialização dos queijos, assim como uma fiscalização eficiente pelos órgãos responsáveis, com o intuito de fornecer produtos que não ofereçam riscos à saúde dos consumidores.

Os dados desse trabalho ressaltam a necessidade de novos estudos com queijos. Sugere-se novas pesquisas voltadas para segurança alimentar por meio da avaliação microbiológica da matéria prima, dos manipuladores e das condições higiênico-sanitárias de equipamentos e instalações com o intuito de assegurar a qualidade sanitária do queijo durante todo o seu processamento.

\section{Referências}

Aguilar, C. E. G., Rossi Jr., O. D., Vidal, A. M. C., Ribeiro, L. F. \& Rossi, G. A. M. (2016). Microbial quality of industrial and retail market grated parmesan cheese in the State of São Paulo, Brazil. Ciência Rural, 46(12), 2257-63. <https://doi.org/10.1590/0103-8478cr20160334>.

Albuquerque, P. P. F., Cezar, R. D. S., Pinheiro Jr., J. W. Nascimento, G. G., Santos, A. S. \& Mota, R. A. (2019). Occurrence of Mycobacterium avium subsp. paratuberculosis in coalho cheese in the State of Pernambuco, Brazil. Arquivo Brasileiro de Medicina Veterinária e Zootecnia. 71(6), 1917-21. < https://doi.org/10.1590/1678-4162-10754>.

Amaral, J. W. Souza, S. M. O. Ribeiro, J. L. Ferreira, M. A \& Poggiani, S. S. C. (2020). Avaliação da qualidade de queijos de produção informal. Segurança Alimentar e Nutricional, Campinas. 27, 1-6. < https://doi.org/10.20396/san.v27i0.8657464>.

Apolinário, T. C. C. Santos, G. S \& Lavorato, J. A. A. (2014). Avaliação da qualidade microbiológica do queijo minas frescal produzido por laticínios do estado de Minas Gerais. Revista Instituto de Laticínios Cândido Tostes, 69 (6), 433-442. <https://doi.org/10.14295/2238-6416.v69i6.290>.

Aragão, B. B. Trajano, S. C. Silva, J. G. Oliveira, J. M. B. Santos, A. S. Melo, R. P. B. Peixoto, R. M \& Mota, R. A. (2020). Avaliação da contaminação por Staphylococcus aureus em queijo coalho artesanal elaborado com leite de cabra produzido no estado de Pernambuco. Arquivo Brasileiro de Medicina Veterinária e Zootecnia, 72(2), 615-622. < https://doi.org/10.1590/1678-4162-10723>. 
Ausani, T. C. Lopes, G. V. Costa, E. F. Corbellini, L. C \& Cardoso, M. (2019). Microbiological quality of colonial cheese sold in Porto Alegre-RS. Semina: Ciências Agrárias, 40 (2), 639-650. < http://dx.doi.org/10.5433/1679-0359.2019v40n2p639>.

Bezerra, D. E. L. Filho, C. R. M. S. Gomes, D. J \& Junior, E. B. P. (2017). Avaliação microbiológica de queijo de coalho comercializado na feira livre de Sousa - Paraíba. Revista Principia, João Pessoa. Divulgação científica e tecnológica do IFPB, nº 37

Bomfim, A. P. Costa, D. B. Silva, I. M. N. Araújo, I. C. S. Andrade, R. A. Galvão, R. S. Cerqueira, V. V. Reis. N \& Santos, M. S. (2020). Qualidade microbiológica e caracterização da resistência de antimicrobiana de bactérias isoladas de queijos coalho comercializados em Vitória da Conquista - Bahia. Segurança Alimentar e Nutricional, Campinas, 27, 1 - 10. e020015. < http://dx.doi.org./10.20396/san.v27i0.86566298>.

Casaril, K. B. P. B. Bento, C. B. P. Henning, K. Pereira, M \& Dias, V. A. (2017). Qualidade microbiológica de salames e queijos coloniais produzidos e comercializados na região sudoeste do Paraná. Revista Brasileira de Agropecuária Sustentável (RBAS), 7(2), 75 - 85.

Dias, B. F. Ferreira, S. M. Carvalho, V. S \& Soares, D. S. B. (2016). Qualidade microbiológica e físico-química de queijo minas frescal artesanal e industrial. Revista de Agricultura Neotropical, Cassilândia-MS, 3(3), 57-64. 10.32404/rean.v3i3.1211.

Galvão, T. F. \& Pereira, M. G. (2014). Revisões sistemáticas da literatura: Passos para sua elaboração. Epidemiologia e Serviços de Saúde, 23(1), 183-184. $<$ http://dx.doi.org/10.5123/S1679-49742014000100018>.

Galvão, M. C. B. \& Ricarte, I. L. M. (2020). Revisão sistemática da literatura: conceituação, produção e publicação. LOGEION: Filosofia da informação, Rio de Janeiro, 6(1), 57-73. < https://doi.org/10.21728/logeion.2019v6n1.p57-73>.

Lima, A. A. \& Cardoso, A. J. V. S. (2019). Qualidade microbiológica de queijo Minas frescal, artesanal, comercializados em feiras livres do Distrito Federal. Brazilian Journal of Development, Curitiba, 5(9), 13673-13688. 10.34117/bjdv5n9-005.

Lopes, V. C. Guedes, E. K. Candioto, M. V. C. Delvino, F. M \& Lima, A. R. (2020). Qualidade microbiológica de queijos tipo Minas comercializados em Belo Horizonte, Infarma, Ciências farmacêuticas, 32, 344-352. http://dx.doi.org/10.14450/2318-9312.v32.e4.a2020.pp344-352>.

Martins, B.R. Tancredi, R. C. P \& Gemal, A. L. (2014). Segurança alimentar no contexto da vigilância sanitária: reflexões e práticas. EPSJV.

Munhoz, I.G.A. Alcântara, V. F. Mergulhão, B. C. R. Pereira, W. A. M. B. Barros, Y. V. R \& Almeida, R. C. (2021). Análise microbiológica comparativa de queijo coalho comercializado em supermercados e feiras livres na Cidade de Maceió - Alagoas. Research, Society and Development, 10(5). < http://dx.doi.org/10.33448/rsd-v10i5.14582>.

Nonato, I. L. Fonseca, V. R. S. Paz, J. G. Nomelini, Q. S. S. Pascoal, G. B \& Souza, D. A. D. (2012). Qualidade higiênico-sanitária de pontos de venda e análise microbiológica de alimentos de rua comercializados no campus Umuarama da Universidade Federal de Uberlândia. Bioscience journal, 28(6), 10611071.

Oliveira, J. J. \& Rezende, M. S. C. (2012). Surtos alimentares de origem bacteriana: uma revisão. Enciclopédia biosfera, Centro Científico Conhecer Goiânia, 9(17), 20132417.

Queiroz, M. M. Rossi, B. F. Castilho, I. G \& Rall, V. L. M. (2017). Hygienic-sanitary quality of Minas fresh cheese sold in the city of Botucatu, São Paulo. Arquivos do Instituto Biológico, 84, 1-6, e0292016. < https://doi.org/10.1590/1808-1657000292016>

Reges, J. T. A. Rodrigues, A. C. B. R. Silva, C. J. Santos, S. M. Maia, A. C. A. C. Tavares, W. R. V. Jesus, M. N \& Silva, S. D. R. (2017). Qualidade microbiológica e físico-química do queijo mussarela a granel comercializadas em Jataí (Goiás, Brasil). Revista Colombiana de Investigaciones Agroindustriales, 4, 69 - 77. < https://doi.org/10.23850/24220582.767>

Santos, B. H. C. Souza, E. L. Sousa, C. P. Serrão, L. H. C \& Amaral, W. C. (2003). Manipuladores como causas potenciais de contaminação de alimento enteral. Infarma, 15, 71-73.

Santos, V. C. Ribeiro, D. C. S. Z \& Fonseca, L. M. (2019). Ocorrência de não conformidades físico-químicas e microbiológicas em leite e derivados no estado de Minas Gerais, no período de 2011 a 2015. Arquivo Brasileiro de Medicina Veterinária e Zootecnia, 71(6), 2111-2116. < https://doi.org/10.1590/16784162-11079>

Soares, D. B.Monteiro, G. P. Fonseca, B. B. Freitas, E A. Mendonça, E. P. Melo, R. T. Iasbeck, J. R \& Rossi, D. A. (2018). Análise sanitária e físico-química e adequação bacteriológica do queijo minas artesanal produzido em duas propriedades. Ciência Animal Brasileira, Goiânia, 19, 1-13, e-36499. < https://doi.org/10.1590/1809-6891v19e-36499>

Sousa, A. Z. B. Abrantes, M. R. Sakamoto, S. M. Silva, J. B. A. Lima, P. O. Lima, R. N. Rocha, M. O. C \& Passos, Y, D. B. (2014). Aspectos físico-químicos e microbiológicos do queijo tipo coalho comercializado em estados do nordeste do Brasil. Arquivos do Instituto Biológico, 81(1), 30-35.

Souza, I. A. Giovannetti, A. C. S. Sanos, L. G. F. Gandra, S. O. S. Martins, M. L \& Ramos, A. L. S. (2017). Qualidade microbiológica de queijo minas frescal comercializado na zona da mata mineira. Revista Instituto de Laticínios Cândido Tostes, Juiz de Fora, 72(3), 152-162. < https://doi.org/10.14295/22386416.v72i3.598>.

Tavares, A. B. Cavalcante, E. A. N. L. D. Timm, C. D. Lima, G. L \& Cereser, N. D. (2019). Queijo artesanal produzido no sul do Rio Grande do Sul: avaliação físico-química, microbiológica e suscetibilidade a antimicrobianos de isolados de staphylococcus coagulase positiva. Ciência Animal Brasileira, Goiânia, 20, 1-10, e-47184. < https://doi.org/10.1590/1089-6891v20e-47184>

Teider junior, P. I. Junior, J. C. R. Ossugui, E. H. Tamanini, R. Ribeiro, J. Santos, G. A. Alfieri, A. A \& Beloti, V. (2019). Pseudomonas spp. and other psychrotrophic microorganisms in inspected and non-inspected Brazilian Minas Frescal cheese: proteolytic, lipolytic and AprX production potential. Pesquisa Veterinária Brasileira, 39(10), 807-815. 10.1590/1678-5150-PVB-6037.

Villas Boas, A. F. Belpiede, E. L. S. Silva, N. R. F. Silva, M. F \& Veiga, S. M. O. M. (2020). Qualidade microbiológica de queijos minas Frescal artesanais e industrializados. Brazilian Journal of Development, Curitiba, 6(10), 83536-83552. 10.34117/bjdv6n10-696.

Vinha, M. B. Pinto, C. L. O. Vanetti, M. C. D. Souza, M. R. M \& Chaves, J. B. P. (2016). Qualidade de queijos Minas Frescal produzidos e comercializados informalmente em agroindústrias familiares. Revista Brasileira de Agropecuária Sustentável (RBAS), 6(4), 51 - 60. 